\title{
Hunting as a management tool? Cougar-human conflict is positively related to trophy hunting
}

Kristine J. Teichman ${ }^{1,2^{*}+}$, Bogdan Cristescu ${ }^{3 \dagger}$ and Chris T. Darimont ${ }^{1,4,5}$

\begin{abstract}
Background: Overexploitation and persecution of large carnivores resulting from conflict with humans comprise major causes of declines worldwide. Although little is known about the interplay between these mortality types, hunting of predators remains a common management strategy aimed at reducing predator-human conflict. Emerging theory and data, however, caution that such policy can alter the age structure of populations, triggering increased conflict in which conflict-prone juveniles are involved.

Results: Using a 30-year dataset on human-caused cougar (Puma concolor) kills in British Columbia (BC), Canada, we examined relationships between hunter-caused and conflict-associated mortality. Individuals that were killed via conflict with humans were younger than hunted cougars. Accounting for human density and habitat productivity, human hunting pressure during or before the year of conflict comprised the most important variables. Both were associated with increased male cougar-human conflict. Moreover, in each of five regions assessed, conflict was higher with increased human hunting pressure for at least one cougar sex.
\end{abstract}

Conclusion: Although only providing correlative evidence, such patterns over large geographic and temporal scales suggest that alternative approaches to conflict mitigation might yield more effective outcomes for humans as well as cougar populations and the individuals within populations.

Keywords: British Columbia, Mountain lion, Predator-human coexistence, Puma, Puma concolor, Skull size, Trophy hunting, Wildlife

\section{Background}

Exploitation and persecution related to conflict with humans form major causes of predator declines worldwide [1-4]. Killing takes several forms and its ecological and evolutionary effects might be more severe than the number of removed predators suggests [5]. Expansion of human activities into previously undisturbed areas enables increased killing through facilitated human access; roads, cut lines and trails associated with extractive industries facilitate hunting of predators during and/or

\footnotetext{
*Correspondence: kristine.teichman@ubc.ca

${ }^{\dagger}$ Kristine J Teichman and Bogdan Cristescu contributed equally to this work

1 Department of Geography, University of Victoria, PO Box 3060, STN CSC, Victoria, BC V8W 3R4, Canada

Full list of author information is available at the end of the article
}

after resource extraction [6, 7]. As human populations expand, the likelihood of wildlife-human conflict also increases [8].

When conflicts involve large mammalian predators that pose a perceived or real threat to humans and property, a common outcome is the lethal removal of the predator by management agencies or sometimes by land owners, for example in response to predation on livestock [9]. In addition, conflict is often managed through increasing human-caused killing of carnivores, under the premise that human hunting can reduce conflict incidence over depredation or decrease predation on wild ungulates sought by hunters (hereafter, 'human hunting hypothesis'; e.g., [10-12]).

In the case of predator-human conflict over depredation, Treves and Naughton-Treves [13] suggested that 
carnivore killing by hunters may actually promote conflict. The process is thought to operate via shifts in age composition to younger age animals, which might depredate more because of higher encounter rates with livestock. This process is thought to occur via the increased mobility of juvenile age classes of carnivores caused by decline in adult male territory tenure [14]. Young individuals become locally more abundant and thereby have increased chance of encountering livestock-and/or young animals might be bolder, more curious or lacking experience in interactions with people [15] or in capturing wild prey effectively [16]. Collectively these factors suggest that younger animals are more conflict-prone (hereafter, 'young animal hypothesis'). Moreover, hunting, culling or other lethal control targeted at specific individuals (e.g. those involved in livestock predation) may reduce conflict ('problem individuals hypothesis'; e.g., [16]), which has been challenged by the assertion that dispersing individuals often quickly recolonize conflict areas, offering only temporary relief [17].

To confront these hypotheses, we examined a longterm dataset on human hunting of cougars and conflict involving cougars in BC, Canada. Cougar-human conflict and cougar hunting are relatively widespread and common, the latter attracting both local BC hunters as well as foreign hunters for guided hunts. We used this system to test whether: (1) cougars killed by hunters would be larger than those that came into conflict with people (young animal hypothesis); and (2) human hunting mortality and conflict incidence would be related (problem animal and human hunting hypotheses).

\section{Methods}

\section{Cougar data}

We used a 30-year dataset (1979-2008) on recorded cougar mortality in BC, Canada provided by the BC Ministry of Environment, wherein all records had an associated date. We used cougar kill records resulting from conflict and legal hunting events. For analyses involving age of conflict and legally hunted cougars [(1) above] we used only those records with associated spatial data, sex and skull sizes. The other analyses [(2) above] were carried out using the larger dataset of spatially-referenced conflict and legal hunting mortalities of cougars with known sex, irrespective of whether skull size had been recorded. Only 96 illegal kills were recorded during 1979-2008, of which 35 had associated skull length and width data and these were not used in analyses. We consider this a minimum estimate because evaluations of the frequency of illegal cougar kills have not been performed. We do not expect illegal killing to vary across regions. Additional spatially-referenced mortality records of cougars with known sex (356, of which 139 had associated skull information) had unclear or unrecorded cause of death and were not used in analyses.

Spatial data included universal transverse mercator (UTM) coordinates and we considered only conflict and legal hunting records occurring within the 5 of 8 total 'development regions' of $\mathrm{BC}$ (region size mean $\pm \mathrm{SE}$, $72,173 \pm 19,388 \mathrm{~km}^{2}$ ) in which mortality was highest (Cariboo, Kootenay, Lower Mainland South-West (SW), Thompson Okanagan and Vancouver Island). After plotting kill locations by region in ArcGIS v.10.3 (ESRI, Redlands, USA) for validation and discarding records occurring outside the 5 regions or in water, as well as a small number of erroneous records (e.g., skull width $>$ skull length), the final dataset for cougar age analysis consisted of 3665 records. The data included records of kills by BC resident hunters and non-resident guided hunters $(n=3219)$ as well as conflict-related cougar deaths $(n=449)$. 'Conflict' was defined as any incident of cougar road mortality, predation on livestock, perceived risk to people such as cougars sighted in urban areas, or recorded attack on humans. More male $(n=2240)$ than female $(n=1428)$ mortality records occurred in the data. The larger dataset for analysis of cougar conflict in relation to human hunting levels included 8788 records. The data were dominated by hunting mortalities $(n=7550)$, with conflict-related kills being less frequent $(n=1238)$. The dataset had more male $(n=5348)$ than female records $(n=3440)$.

Skull size data (length and width in $\mathrm{mm}$ ) were collected by BC Ministry of Environment personnel as a proxy for age. These variables are positively correlated [18] with the skull growth continuing long into adulthood [19]. Skull size has been used as a proxy for age/body size in other large felids, such as African lion [20], leopard [21] and jaguar [22]. Because skull length and width were highly correlated for males (Pearson $r=0.761, d f=2239$, $P<0.001)$ and females $(r=0.669, d f=1427, P<0.001)$, we used an index known as the total skull length (or total skull size) for all analyses. This index is the sum of length and width [22] and is the standard age/body/trophy size metric used by the Boone and Crockett Club and the International Council for Game and Wildlife Conservation when assessing cougar and jaguar trophies [23].

\section{Statistical analyses}

To assess if skull sizes varied in relation to different human-caused mortality types, we first assessed if the variable was normally distributed with Shapiro-Wilk tests. Separate assessments were carried out for each sex and region. For males and females in all regions, the skull size variable was not normally distributed. Therefore we used two-sample Wilcoxon rank-sum (Mann-Whitney) tests to compare mean skull size for conflict and hunter 
kills. Separate testing was performed for each sex and region for a total of 10 tests ( 2 sexes $\times 5$ regions).

We used time series analysis to test factor combinations hypothesized a priori to influence annual conflict frequency across time (Additional file 1: Table S1). Newey-West Heteroskedasticity and Autocorrelation (HAC) standard errors were computed in multiple linear regression to account for potential variability and temporal autocorrelation in the models' error terms. Conflict incidence (dependent variable) was standardized per $10,000 \mathrm{~km}^{2}$ and square root-transformed prior to modelling to reduce skewness. Predictor variables included human density (D), human hunting pressure (annual number of cougars hunted) in the year of conflict $\left(\mathrm{H}_{\mathrm{t} 0}\right)$ and the Normalized Difference Vegetation Index (NDVI; a proxy for plant and prey productivity) in the year of conflict $\left(\mathrm{N}_{\mathrm{t} 0}\right)$. A squared term was included for human density $\left(\mathrm{D}^{2}\right)$ to account for possible thresholds in human density beyond which conflict would decrease because of an assumed limitation to cougar habitat. Yearly lag 1 and 2 terms were used for human hunting pressure $\left(\mathrm{H}_{\mathrm{t} 1}\right.$; $\left.\mathrm{H}_{\mathrm{t} 2}\right)$ and NDVI $\left(\mathrm{N}_{\mathrm{t} 1} ; \mathrm{N}_{\mathrm{t} 2}\right)$ to incorporate potential influences of hunting and habitat productivity in the periods preceding conflict. Human density (per $10,000 \mathrm{~km}^{2}$ ) was calculated for each year by dividing annual census counts by region size (details in Additional file 2). Human density calculation for the Vancouver Island region included a small part of the mainland coast as constrained by data availability. Human hunting pressure was standardized per $10,000 \mathrm{~km}^{2}$ and included hunting by residents and non-residents of BC. Because habitat quality and prey availability can influence large carnivore-human conflict $[24,25]$, but such data over our broad temporal and spatial extents were not available, we used NDVI as a habitat productivity surrogate [26-28]. These data came from the National Oceanic and Atmospheric Administration (NOAA) Climate Data Records (CDR), which derived NDVI from surface reflectance data acquired by the advanced very high resolution radiometer (AVHRR) sensor ([29]; details in Additional file 2). Highly correlated variables $(r>|0.8|)$ were not included together in the same model structure.

We evaluated candidate models using Akaike's Information Criterion for small sample sizes (AICc) [30]. We estimated relative importance of variables by applying multi-model inference to rank variables in the supported model set $(\triangle \mathrm{AICc} \leq 7)$ by their summed AICc weights [31]. We used the proportion of variance explained $\left(R^{2}\right)$ to evaluate model performance. For all models that received support we plotted residuals against fitted values and inspected for patterns in the residual distribution. We used Stata v.14.1 (StataCorp, College Station, USA) and an alpha level of 0.10 for all statistical analyses.
The Newey-West HAC standard errors were computed in Stata using the hacreg command [32].

\section{Results \\ Skull size comparisons between hunter- and conflict-killed cougars}

At the provincial level, conflict-killed male cougar skulls were smaller than those of hunter-killed animals (Twosample Wilcoxon rank-sum $z=-5.376, d f=2239$, $P<0.001)$. Skull sizes differed between kill types for males in 4 of the $5 \mathrm{BC}$ regions, similarly larger for hunter-killed than for conflict-killed males for Cariboo (Two-sample Wilcoxon rank-sum $z=-1.959, d f=329$, $P=0.050$ ), Lower Mainland SW (Two-sample Wilcoxon rank-sum $z=-2.195, d f=113, P=0.028)$, Thompson Okanagan (Two-sample Wilcoxon rank-sum $z=-2.210$, $d f=763, P=0.027$ ) and Vancouver Island (Two-sample Wilcoxon rank-sum $z=-2.762, d f=571, P=0.006$ ) (Fig. 1a).

At the provincial level, skull sizes of females were similarly smaller among conflict animals compared with hunter-killed individuals (Two-sample Wilcoxon ranksum $z=-3.464, d f=1427, P<0.001)$. Skull sizes likewise differed between kill types in 2 of the $5 \mathrm{BC}$ regions (Lower Mainland SW; Two-sample Wilcoxon rank-sum $z=-1.701, d f=114, P=0.089$; Thompson Okanagan; Two-sample Wilcoxon rank-sum $z=-4.311, d f=520$, $P<0.001$ ) (Fig. 1b).

\section{Predictors of cougar-human conflict}

Regional models (see Additional file 3) that received substantial support explained roughly half of the variation in cougar-human conflict for males $\left(R^{2}:\right.$ mean $=0.504$; range $=0.258-0.816$; all $P<0.10)$ as well as females $\left(R^{2}\right.$ : mean $=0.507$; range $=0.124-0.772$; all $P<0.10$ ). For both sexes, models that received substantial support were of intermediate or low complexity (with 1-4 parameters, including the intercept; Table 1). Only for males in the Lower Mainland SW did the intercept-only model receive substantial support, but two candidate models were superior. All supported models $(\triangle \mathrm{AICc} \leq 7)$ [33] are listed in Additional file 4: Tables S2-S6, provided their $\triangle \mathrm{AICc}$ was smaller than that of the corresponding null model.

Human hunting pressure in both current (Figs. 2, 3) and lagged periods (Fig. 2) had the most relative importance for predicting cougar-human conflict for male cougars across the five regions. Human hunting was positively associated with conflict involving this cougar sex. Variables for human hunting during the conflict year or hunting lagged occurred in all but one male model that received substantial support and which had AICc less than the null model's AICc (Table 1). 


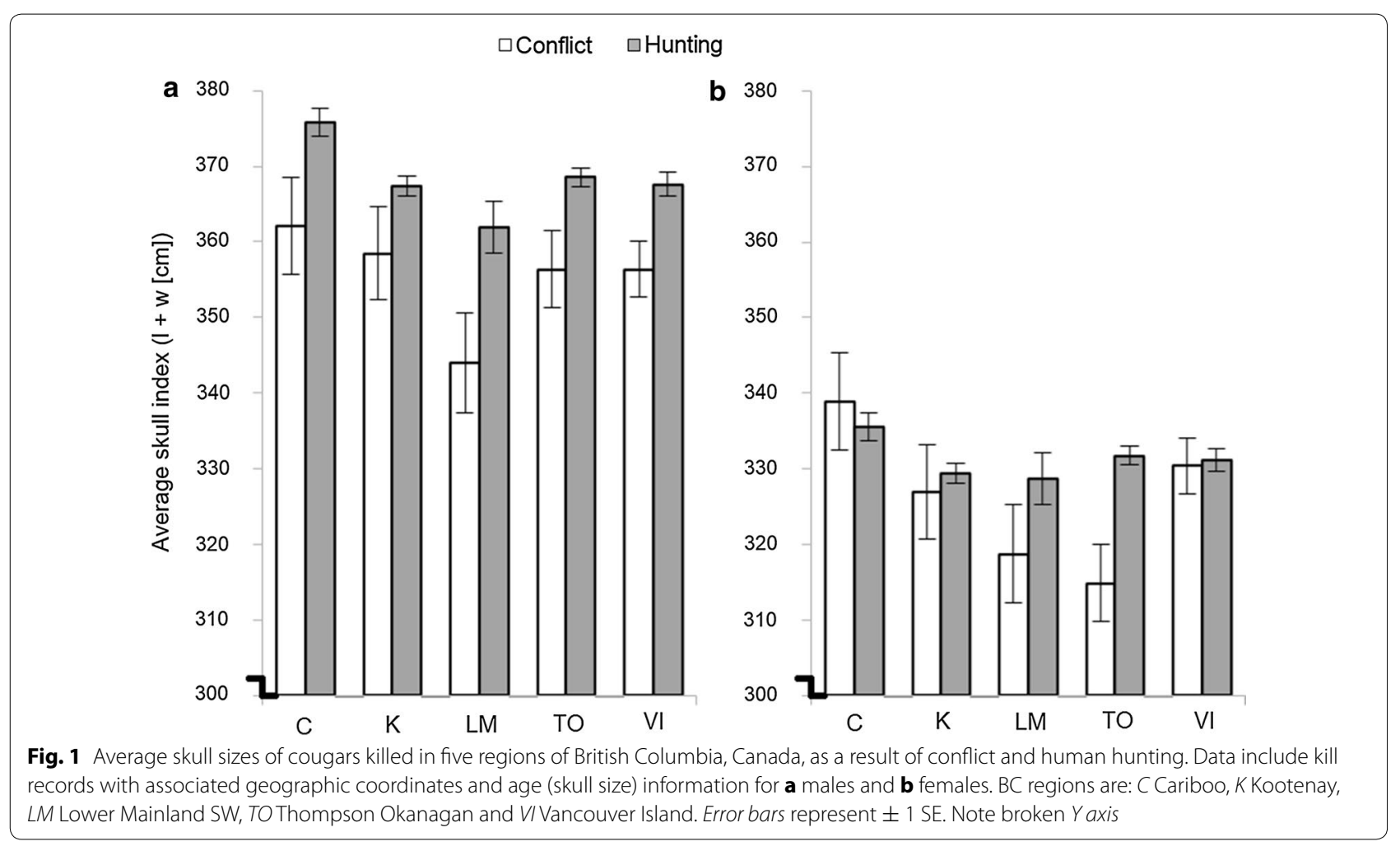

Table 1 Models for assessing temporal patterns of cougarhuman conflict in British Columbia, Canada that received substantial support $(\Delta A \mid C c<2)$

\begin{tabular}{|c|c|c|c|c|c|}
\hline Region & Sex & $\begin{array}{l}\text { Model } \\
\text { description }\end{array}$ & $\Delta \mathrm{AICc}$ & $w_{\text {AICC }}$ & $\mathrm{R}^{2}$ \\
\hline \multirow[t]{4}{*}{ Cariboo } & \multirow[t]{3}{*}{ Male } & $\mathrm{D}+\mathrm{D}^{2}+\mathrm{H}_{\mathrm{t} 0}$ & 0.0 & 0.33 & 0.557 \\
\hline & & $D+D^{2}$ & 1.0 & 0.20 & 0.456 \\
\hline & & $\mathrm{H}_{\mathrm{t} 0}$ & 1.1 & 0.19 & 0.369 \\
\hline & Female & $D+D^{2}$ & 0.0 & 0.64 & 0.599 \\
\hline \multirow[t]{3}{*}{ Kootenay } & Male & $\mathrm{N}_{\mathrm{t} 0}+\mathrm{H}_{\mathrm{t} 0}$ & 0.0 & 0.82 & 0.816 \\
\hline & \multirow[t]{2}{*}{ Female } & $D+D^{2}$ & 0.0 & 0.48 & 0.736 \\
\hline & & $\mathrm{N}_{\mathrm{t} 0}+\mathrm{D}+\mathrm{D}^{2}$ & 0.3 & 0.42 & 0.772 \\
\hline \multirow{3}{*}{$\begin{array}{l}\text { Lower Mainland } \\
\text { SW }\end{array}$} & \multirow[t]{2}{*}{ Male } & $\mathrm{H}_{\mathrm{t} 1}+\mathrm{H}_{\mathrm{t} 2}$ & 0.0 & 0.19 & 0.258 \\
\hline & & $\mathrm{H}_{\mathrm{t} 0}+\mathrm{H}_{\mathrm{t} 1}+\mathrm{H}_{\mathrm{t} 2}$ & 0.6 & 0.14 & 0.347 \\
\hline & Female & $D+D^{2}$ & 0.0 & 0.46 & 0.334 \\
\hline \multirow{4}{*}{$\begin{array}{l}\text { Thompson } \\
\text { Okanagan }\end{array}$} & Male & $\mathrm{D}+\mathrm{D}^{2}+\mathrm{H}_{\mathrm{t} 0}$ & 0.0 & 0.51 & 0.590 \\
\hline & \multirow[t]{3}{*}{ Female } & $\mathrm{H}_{\mathrm{t} 0}+\mathrm{H}_{\mathrm{t} 1}+\mathrm{H}_{\mathrm{t} 2}$ & 0.0 & 0.30 & 0.406 \\
\hline & & $\mathrm{H}_{\mathrm{t} 0}$ & 1.8 & 0.12 & 0.124 \\
\hline & & $D+D^{2}$ & 1.8 & 0.12 & 0.236 \\
\hline \multirow[t]{4}{*}{ Vancouver Island } & \multirow[t]{2}{*}{ Male } & $\mathrm{H}_{\mathrm{t} 1}+\mathrm{H}_{\mathrm{t} 2}$ & 0.0 & 0.35 & 0.539 \\
\hline & & $\mathrm{H}_{\mathrm{t} 0}+\mathrm{H}_{\mathrm{t} 1}+\mathrm{H}_{\mathrm{t} 2}$ & 0.2 & 0.32 & 0.602 \\
\hline & \multirow[t]{2}{*}{ Female } & $\mathrm{H}_{\mathrm{t} 0}$ & 0.0 & 0.50 & 0.668 \\
\hline & & $\mathrm{N}_{\mathrm{t} 0}+\mathrm{H}_{\mathrm{t} 0}$ & 1.6 & 0.23 & 0.688 \\
\hline
\end{tabular}

$D$ human density, $H_{t 0}$ human hunting pressure, $H_{t 1}$ Human hunting pressure (lag $1), H_{t 2}$ human hunting pressure (lag 2), $N_{t 0} \mathrm{NDVI}, N_{t 1} \mathrm{NDVI}(\operatorname{lag} 1), N_{t 2} \mathrm{NDVI}(\operatorname{lag} 2)$
Human hunting pressure was also the most important factor associated with cougar-human conflict for female cougars in 2 of $5 \mathrm{BC}$ regions. Only for one model (female cougars, Thompson-Okanagan) was increased human hunting (lag 2) associated with decreased conflict.

Overall, increased human hunting was related to greater conflict for 16 of 17 models that included hunting variables with estimates that did not overlap zero and that received substantial support (Table 2; Additional file 4: Tables S7-S11).

Human density was the key variable associated with conflict for female cougars in $3 \mathrm{BC}$ regions (Fig. 2) and was also important for male cougar-human conflict in 1 $\mathrm{BC}$ region (Table 2). Years with intermediary human densities were generally associated with conflict (Additional file 4: Tables S9, S10). For both cougar sexes, NDVI was the least important variable tested in relation to conflict (Fig. 2), but three substantially supported models revealed conflict increases in years when habitat productivity was low (Table 2).

\section{Discussion}

With expanding human populations and influence, conflict between carnivores and humans is expected to increase, which requires evidence-informed approaches to conflict mitigation. A long-term data set on humancaused cougar mortality allowed us to confront 


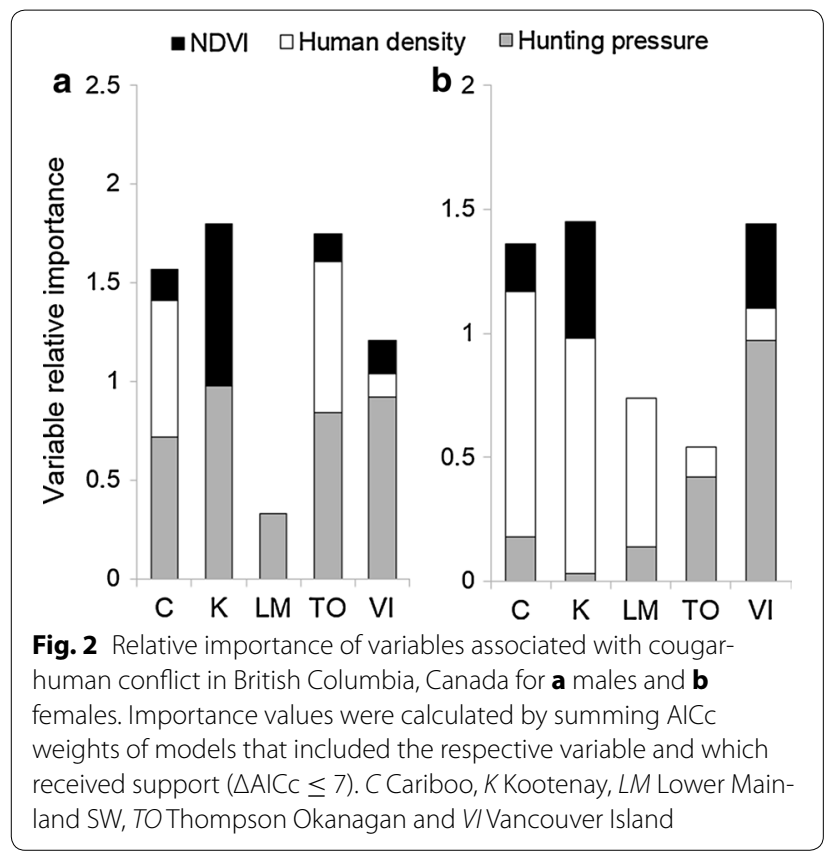

fundamental hypotheses on the relationship between human hunting, cougar-human conflict and cougar population demography, including testing of the commonly accepted but under-examined assumption that hunting of large carnivores could result in decreased conflict incidence (see [34] for an overview and call for inquiry into the relationship between hunting of carnivores and conflict).

As we expected, we found support for the young animal hypothesis in most comparisons, with individuals that came into conflict with humans younger compared to those hunted. Human encroachment into cougar habitat increases conflict potential [35-37] and young animals are more likely to occur in areas used by people than other age classes [38]. Dispersing juveniles are more likely to come into conflict on travel routes through fragmented habitats and high risk areas including human inhabited areas, roads [39] and ranches [24, 40]. In addition, food resources may be limited while dispersers attempt to establish home ranges [41]. As a result, when available, cougars may attack livestock [42] (however, see [43] for an alternative documentation of old cougars being disproportionately involved in livestock predation). Finally, hunters might be more likely to forgo killing small individuals for trophies, particularly if they are treed by trained hounds, although this has not been examined.

The manner by which carnivore populations respond to regulated hunting depends on social structure, reproductive strategies and dispersal patterns [14]. Human hunting of old individuals can increase immigration of juveniles from neighboring areas [14, 44], which could result in increased conflict. We therefore hypothesized that increased human hunting pressure would be associated with increased conflict via social disruption and younger population age structure (problem animal and human hunting hypotheses). We demonstrated that high hunting-related mortality in the same or preceding time period is positively associated with cougar-human conflict for at least one sex in all five regions tested (Table 2; Figs. 2, 3), with the most consistent pattern (both sexes: regression $P<0.10$ ) for Thompson-Okanagan and Vancouver Island. While Thompson-Okanagan is an inland region, Vancouver Island is a large land mass off the British Columbia mainland known to be the world's 'hotspot' of cougar-human conflict [45]. Our results corroborate and extend recent findings on impacts of human hunting on cougar complaints and depredations in Washington State [46]. In British Columbia, male cougars appeared most susceptible to conflict if hunted more intensively and conflict records involving males were almost double
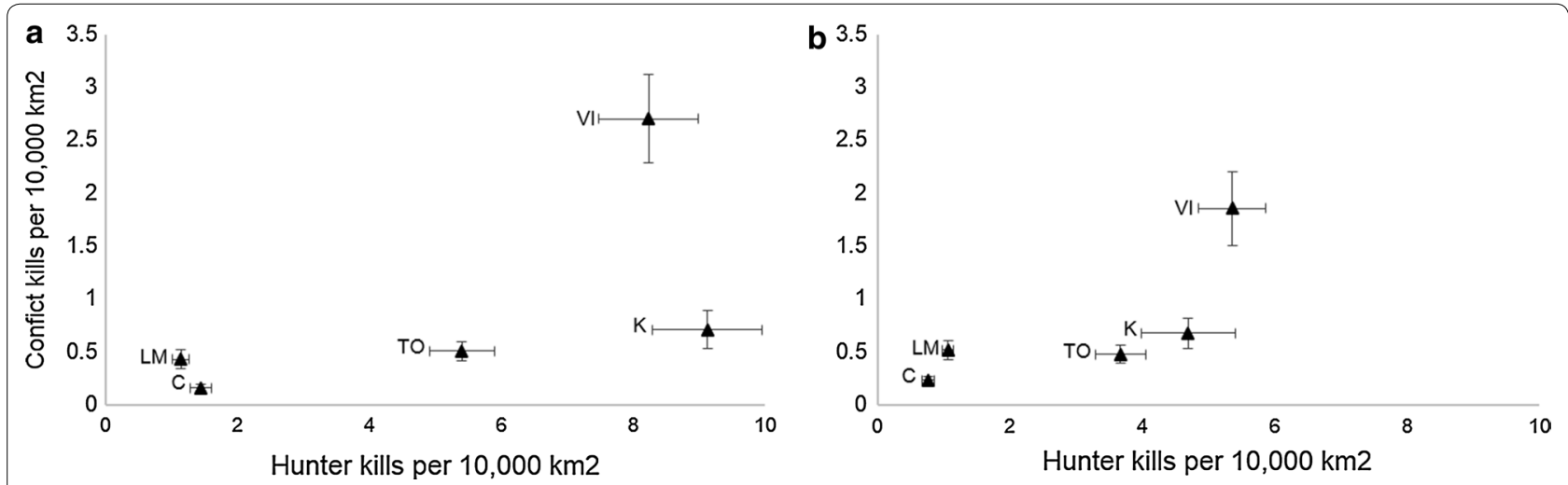

Fig. 3 Mean ( $\pm 1 \mathrm{SE}$ ) annual conflict-killed relative to hunter-killed cougars per 10,000 km² in five regions of British Columbia, Canada. Data are for a males and $\mathbf{b}$ females. C Cariboo, K Kootenay, LM Lower Mainland SW, TOThompson Okanagan and VIVancouver Island 
Table 2 Direction (+ positive, - negative) and confidence interval overlap with zero for parameter estimates from substantially supported $\triangle \mathrm{AIC}$ models for cougar-human conflict in British Columbia, Canada

\begin{tabular}{|c|c|c|c|c|c|c|c|c|c|}
\hline Region & Sex & $\mathrm{N}_{\text {to }}$ & $\mathrm{N}_{\mathrm{t} 1}$ & $\mathrm{~N}_{\mathrm{t} 2}$ & D & $D^{2}$ & $\mathrm{H}_{\mathrm{to}}$ & $\mathrm{H}_{\mathrm{t} 1}$ & $\mathrm{H}_{\mathrm{t} 2}$ \\
\hline \multirow[t]{2}{*}{ Cariboo } & Male & & & & ++ & -- & $+^{*}+^{*}$ & & \\
\hline & Female & & & & + & - & & & \\
\hline \multirow[t]{2}{*}{ Kootenay } & Male & $-^{*}$ & & & & & $+^{*}$ & & \\
\hline & Female & $-^{*}$ & & & $--^{*}{ }^{*}$ & $+^{*}+{ }^{*}$ & & & \\
\hline \multirow[t]{2}{*}{ Lower Mainland SW } & Male & & & & & & $+^{*}$ & $+^{*}+{ }^{*}$ & -- \\
\hline & Female & & & & $+^{*}$ & $-^{*}$ & & & \\
\hline \multirow[t]{2}{*}{ Thompson Okanagan } & Male & & & & $+^{*}$ & $-^{*}$ & $+^{*}$ & & \\
\hline & Female & & & & $+^{*}$ & $-^{*}$ & $+^{*}+{ }^{*}$ & - & $-^{*}$ \\
\hline \multirow[t]{2}{*}{ Vancouver Island } & Male & & & & & & $+^{*}$ & $+^{*}+*$ & $+^{*}+{ }^{*}$ \\
\hline & Female & $-^{*}$ & & & & & $+^{*}+{ }^{*}$ & & \\
\hline
\end{tabular}

Estimates for which confidence intervals did not overlap zero have an asterisk. No reporting of coefficients refers to the specific variable(s) not being included in supported models

$D$ human density, $H_{t 0}$ human hunting pressure, $H_{t 1}$ Human hunting pressure (lag 1$), H_{t 2}$ human hunting pressure (lag 2$), N_{t 0} N D V I, N_{t 1} N D V I(l a g ~ 1), N_{t 2} N D V I(l a g 2)$

in number than those involving females. The latter findings are in accordance with Linnell et al.'s conclusion that male large carnivores are most likely to get into conflict with humans [16], a proposition also more recently supported by research on cheetah-human [47] and jaguarhuman conflicts [48]. One mechanism that might explain why males of hunted cougar populations are involved more frequently in conflicts than females might be the altered male spatial organization under greater hunting pressure [49].

Human densities were associated with male cougarhuman conflict in only one $\mathrm{BC}$ region, whereas conflict with females appeared related to variation in human density. Females might use suboptimal areas with human development by means of spatially avoiding male-caused mortality risk for themselves and their offspring, possibly resulting in increased conflict for females in connection to human densities, as we detected. Selection of areas close to human development by females with offspring presumably to avoid males has been recently documented for cougars in California [50] and grizzly bears in Alberta [51]. Thompson-Okanagan was the only region where human density was related with conflict for both sexes, with conflicts most likely at intermediary densities of people. Such intermediate densities are typically found in exurban or suburban areas and are thought to have high levels of cougar-human conflict in California [52]. Despite high human populations in Lower Mainland SW, human density in this region did not influence frequency of conflict involving males. The documented decreases in conflict associated with decreased human hunting of males in this region suggest that, similar to other carnivores [53], cougar populations can persist in regions with high human densities as long as human hunting pressure is low.
We found limited relationship with NDVI, our proxy for habitat productivity. Decreased productivity was hypothesized to be associated with increased cougarhuman conflict. Conversely, a positive relation between conflict and NDVI might have been expected due to increased productivity resulting in increased reproductive output [54], with the indirect effect of increased subadult dispersal and greater conflict potential. Kootenay was the only region where decreased productivity was associated with increased conflict for both males and females. This region comprises substantial high elevation mountain ranges compared to the other regions and habitat productivity in the Kootenay is possibly an important limiting factor for cougars and their prey. Future monitoring of the associations between habitat productivity and carnivore-human conflict should not be neglected, given increased variability in vegetation conditions/ NDVI associated with climate change, which might have implications for future predator-human conflicts that have yet to be explored. When possible, finer scale prey availability metrics should be incorporated, because prey use differences among cougar sexes [55] could influence conflict incidence. Furthermore, it is important to recognize that inferences from this study should be placed in the context of the relative coarseness of covariate data utilized, which is to be expected when focusing on broad spatiotemporal extents such as the one we considered. Our results showed that human-related variables had the strongest association with conflict. We acknowledge that the patterns of association we reveal do not necessarily imply causation. Our results, however, are generally consistent with the hypothesis that high hunter mortality leads to young animals becoming involved in conflict. Unlike natural agents of mortality (other predators, 
competitors, disease), hunters typically target adult individuals. The ability of resident males to maintain territories means that sub-adults are more likely to come into conflict, likely because of their movements during dispersal in search for vacant territories [56]. Human hunting can disrupt social structure leading to increased juvenile immigration from surrounding source populations [14] and result in younger age structure $[57,58]$ exacerbating conflicts between cougars and humans. With increasing human populations, interactions between predators and humans are expected to become more common, underlining the need for research into patterns and mechanisms of conflict, conflict prevention and non-traditional management strategies to facilitate coexistence.

\section{Conclusions}

Wildlife managers often prescribe hunting of carnivores to reduce competition with hunters for prey and to minimize conflicts with humans and their property [8]. If lethal control such as through human hunting is to facilitate coexistence between wildlife and humans, control must minimize wildlife-human conflict or increase tolerance of the public towards wildlife, without compromising wildlife population viability [13]. In some situations lethal management focused on targeted individuals associated with conflict (e.g., individuals that injure or kill people in predatory attacks) offers one route to address large carnivore-human conflicts. However, we showed that overall increased human hunting in fact can be associated with increased conflict, especially for males. Although our results are only correlative, we caution against the universal use of hunting as a tool for managing conflict with large predators.

\section{Additional files}

Additional file 1: Table S1. Hypotheses for frequency of cougar-human conflict.

Additional file 2. Information on NDVI and human density data.

Additional file 3. Information on regional models of cougar-human conflict.

Additional file 4: Tables S2-S11. List of all cougar-human conflict models that received support $(\triangle \mathrm{AIC} \leq 7)$. Estimated coefficients from substantially supported $(\triangle \mathrm{AICC}<2)$ models are also listed.

\footnotetext{
Abbreviations

AICc: Akaike's information criterion for small sample sizes; AVHRR: advanced very high resolution radiometer; BC: British Columbia; CDR: climate data records; D: human density; HAC: heteroskedasticity and autocorrelation; $\mathrm{H}_{\mathrm{t} 0}$ : human hunting pressure; $\mathrm{H}_{\mathrm{t} 1}$ : human hunting pressure (lag 1); $\mathrm{H}_{\mathrm{t} 2}$ : human hunting pressure (lag 2); NDVI: normalized difference vegetation index; NOAA: national oceanic and atmospheric administration; $\mathrm{N}_{\mathrm{to}}$ : NDVI; $\mathrm{N}_{\mathrm{t} 1}$ : NDVI (lag 1); $\mathrm{N}_{\mathrm{t} 2}$ : NDVI (lag 2); SW: south-west; UTM: universal transverse mercator; $\triangle \mathrm{AICC}$ : difference between the model AICc and the lowest AICc for the model set.
}

\section{Authors' contributions}

KJT and BC conceived and designed the study and CTD helped to refine it. KJT obtained the cougar mortality dataset from the British Columbia Ministry of Environment. KJT and BC performed the statistical analyses. KJT, BC and CTD wrote the manuscript. All authors reviewed and approved the final manuscript.

\section{Author details}

${ }^{1}$ Department of Geography, University of Victoria, PO Box 3060, STN CSC, Victoria, BC V8W 3R4, Canada. ${ }^{2}$ Biology Department, University of British Columbia, 3333 University Way, Kelowna, BC V1V 1V7, Canada. ${ }^{3}$ Department of Biological Sciences, University of Cape Town, Private Bag X3, Rondebosch 7701, South Africa. ${ }^{4}$ Raincoast Conservation Foundation, P.O. Box 77, Bella Bella, BC VOT 1B0, Canada. ${ }^{5}$ Hakai Institute, P.O. Box 309, Heriot Bay, BC VOP $1 \mathrm{HO}$, Canada.

\section{Acknowledgements}

We thank Tony Hamilton for providing the Ministry of Environment cougar mortality data for British Columbia, Canada.

\section{Competing interests}

The authors declare that they have no competing interests.

\section{Availability of data and materials}

The dataset used is available upon request from the authors, pending permission to redistribute from the British Columbia Ministry of Environment, Canada.

\section{Ethics (and consent to participate)}

This study did not require ethics approval as it made use of an existing dataset collected by the British Columbia Ministry of Environment, Canada.

Received: 21 May 2016 Accepted: 27 September 2016

Published online: 11 October 2016

\section{References}

1. Woodroffe R, Ginsberg J. Edge effects and the extinction of populations inside protected areas. Science. 1998;280:2126-8.

2. Schipper J, Chanson JS, Chiozza F, Cox NA, Hoffmann M, Katariya V, Lamoreux J, Rodrigues ASL, Stuart SN, Temple HJ, et al. The status of the world's land and marine mammals: diversity, threat, and knowledge. Science. 2008;322:225-30.

3. Fa JE, Brown D. Impacts of hunting on mammals in African tropical moist forests: a review and synthesis. Mamm Rev. 2009;39:231-64.

4. Ripple WJ, Estes JA, Beschta RL, Wilmers CC, Ritchie EG, Hebblewhite M, Berger J, Elmhagen B, Letnic M, Nelson MP, Schmitz OJ, Smith DW, Wallach AD, Wirsing AJ. Status and ecological effects of the world's largest carnivores. Science. 2014. doi:10.1126/science.1241484.

5. Krofel M, Treves A, Ripple WJ, Chapron G, López-Bao JV. Hunted carnivores at outsized risk. Science. 2015;30:518-9.

6. Brinkman TJ, Chapin T, Kofinas G, Person DK. Linking hunter knowledge with forest change to understand changing deer harvest opportunities in intensively logged landscape. Ecol Soc. 2009;14. http://www.ecologyandsociety.org/vol14/iss1/art36/.

7. Festa-Bianchet M, Ray JC, Boutin S, Cote SD, Gunn A. Conservation of caribou (Rangifer tarandus) in Canada: an uncertain future. Can J Zool. 2011;89:419-34.

8. Treves A, Karanth KU. Human-carnivore conflict and perspectives on carnivore management worldwide. Conserv Biol. 2003;17:1491-9.

9. Treves A, Wallace RB, Naughton-Treves L, Morales A. Co-managing human-wildlife conflicts: a review. Hum Dim Wildl. 2006;11:383-96.

10. Linnell JDC, Andersen R, Kvam T, Andren H, Liberg O, Odden J, Moa PF. Home range size and choice of management strategy for lynx in Scandinavia. Environ Manage. 2001;27:869-79.

11. Schwartz CC, Swenson JE, Miller SD. Large carnivores, moose, and humans: a changing paradigm of predator management in the $21 \mathrm{st}$ century. Alces. 2003;39:41-63. 
12. Sidorovich VE, Tikhomirova LL, Jedrzejewska B. Wolf Canis lupus numbers, diet and damage to livestock in relation to hunting and ungulate abundance in northeastern Belarus during 1999-2000. Wildl. Biol. 2003;9:103-11.

13. Treves A, Naughton-Treves L. Evaluating lethal control in the management of human-wildlife conflict. In: Woodroffe R, Thirgood S, Rabinowitz A, editors. People and wildlife: conflict or coexistence?. Cambridge: Cambridge University Press; 2005.

14. Robinson HS, Wielgus RB, Cooley HS, Cooley SW. Sink populations in carnivore management: cougar demography and immigration in a hunted population. Ecol Appl. 2008;18:1028-37.

15. Elfström M, Zedrosser A, Støen O-G, Swenson JE. Ultimate and proximate mechanisms underlying the occurrence of bears close to human settlements: review and management implications. Mamm Rev. 2014;44:5-18.

16. Linnell JDC, Odden J, Smith ME, Aanes R, Swenson JE. Large carnivores that kill livestock: Do "problem individuals" really exist? Wildl Soc Bull. 1999;27:698-705.

17. Conner MM, Jaeger MM, Weller TJ, McCullough DR. Effect of coyote removal on sheep depredation in Northern California. J Wildl Manage. 1998;62:690-9.

18. Gay SW, Best TL. Age-related variation in skulls of the puma (Puma concolor). J Mammal. 1996;77:191-8.

19. Segura V, Prevosti F, Cassini G. Cranial ontogeny in the Puma lineage, Puma concolor, Herpailurus yagouaroundi, and Acinonyx jubatus (Carnivora: Felidae): a three-dimensional geometric morphometric approach. Zool J Linnean Soc. 2013;169:235-50.

20. Smuts GL, Robinson GA, Whyte IJ. Comparative growth of wild male and female lions (Panthera leo). J Zool. 1980;190:365-73.

21. Lukarevsky V, Malkhasyan A, Askerov E. Biology and ecology of the leopard in the Caucasus. CAT News Special Issue 2-Caucasus Leopard. 2007;9-14.

22. Hoogesteijn R, Mondolfi E. Body mass and skull measurements in four jaguar populations and observations on their prey base. Bull Florida Museum Nat Hist. 1996:39:195-219.

23. Whitehead GK. The game-trophies of the world -international formula for the measurement and evaluation of trophies. Hamburg and Berlin: Verlag Paul Parey; 1981

24. Polisar J, Matix I, Scognamillo D, Farrell L, Sunquist ME, Eisenberg JF. Jaguars, pumas, their prey base, and cattle ranching: ecological interpretations of a management problem. Biol Conserv. 2003;109:297-310.

25. Packer C, Ikanda D, Kissui B, Kushnir H. Conservation biology: lion attacks on humans in Tanzania. Nature. 2005;436:927-8.

26. Pettorelli N, Pelletier F, von Hardenberg A, Festa-Bianchet M, Côté SD. Early onset of vegetation growth vs. rapid green-up: impacts on juvenile mountain ungulates. Ecology. 2007:88:381-90.

27. Hamel S, Garel M, Festa-Bianchet M, Gaillard J-M, Côté SD. Spring normalized difference vegetation index (NDVI) predicts annual variation in timing of peak faecal crude protein in mountain ungulates. J Appl Ecol. 2009;46:582-9.

28. Pettorelli N, Ryan S, Mueller T, Bunnefeld N, Jedrzejewska B, Lima M, Kausrud $K$. The normalized difference vegetation index (NDVI): unforeseen successes in animal ecology. Clim Res. 2011;46:15-27.

29. United States geological survey. Earth explorer. vegetation monitoringNOAA CDR NDVI. http://earthexplorer.usgs.gov/ Accessed 20 July 2016.

30. Burnham KP, Anderson DR. Model selection and multimodel inference: practical information-theoretic approach. 2nd ed. New York: SpringerVerlag; 2002

31. Symonds MRE, Moussalli A. A brief guide to model selection, multimodel inference and model averaging in behavioural ecology using Akaike's information criterion. Behav Ecol Sociobiol. 2011;65:13-21.

32. Wang $Q$, Wu N. Long-run covariance and its applications in cointegration regression. The Stata J. 2012;12:515-42.

33. Grueber CE, Nakagawa S, Lewis RJ, Jamieson IG. Multimodel inference in ecology and evolution: challenges and solutions. J Evol Biol. 2010;24:699-711.

34. Treves A. Hunting for large carnivore conservation. J Appl Ecol. 2009;46:1350-6.

35. Beier P. Determining minimum habitat areas and habitat corridors for cougars. Conserv Biol. 1993;7:94-108.

36. Torres SG, Mansfield TM, Foley JE, Ludo T, Branches A. Mountain lion and human activity in California: testing speculations. Wildl Soc Bull. 1996:24:451-60.
37. Weaver $J$, Paquet PC, Ruggiero LF. Resilience and conservation of large carnivores in the Rocky Mountains. Conserv Biol. 1996;10:964-76.

38. Kertson BN, Spencer RD, Grue CE. Demographic influences on cougar residential use and interactions with people in western Washington. $J$ Mammal. 2013:94:269-81.

39. Teichman KJ, Cristescu B, Nielsen SE. Does sex matter? Temporal and spatial patterns of cougar-human conflict in British Columbia. PLoS ONE. 2013;8:e74663.

40. Michalski F, Boulhosa RLP, Faria A, Peres CA. Human-wild life conflicts in a fragmented Amazonian forest landscape: determinants of large felid depredation on livestock. Anim Conserv. 2006:9:179-88.

41. Hornocker M. Pressing business. In: Hornocker M, Negri S, editors. Cougar ecology and conservation. Chicago: University of Chicago Press; 2010. p. 235-47.

42. Cunningham SC, Gustavson CR, Ballard WB. Diet selection of mountain lions in southeastern Arizona. J Range Manage. 1999;52:202-7.

43. FairaizI SD, Stiver SJ. A profile of depredating mountain lions-proceedings of the seventeenth vertebrate pest conference. Davis: University of California Press; 1996.

44. Wielgus RB, Sarrazin F, Ferriere R, Clobert J. Estimating effects of adult male mortality on grizzly bear population growth and persistence using matrix models. Biol Conserv. 2001:98:293-303.

45. Beier P. Cougar attacks on humans in the United-States and Canada. Wildl Soc Bull. 1991;19:403-12.

46. Peebles KA, Wielgus RB, Maletzke BT, Swanson ME. Effects of remedial sport hunting on cougar complaints and livestock depredations. PLoS ONE. 2013:8:e79713.

47. Marker LL, Dickman AJ, Leo RM, Mills MGL, MacDonald DW. Demography of the Namibian cheetah Acinonyx jubatus jubatus. Biol Conserv. 2003;114:413-25.

48. Conde DA, Colchero F, Zarza H, Christensen NL Jr, Sexton JO, Manterola C, Chávez C, Rivera A, Azuara D, Ceballos G. Sex matters: modeling male and female habitat differences for jaguar conservation. Biol Conserv. 2010;143:1980-8

49. Maletzke BT, Wielgus R, Koehler GM, Swanson M, Cooley H, Alldredge JR. Effects of hunting on cougar spatial organization. Ecol Evol. 2014;4:2178-85.

50. Benson JF, Sikich JA, Riley SPD. Individual and population level resource selection patterns of mountain lions preying on mule deer along an urban-wildland gradient. PLoS ONE. 2016;11:e0158006.

51. Cristescu B, Stenhouse GB, Symbaluk M, Nielsen SE, Boyce MS. Wildlife habitat selection on landscapes with industrial disturbance. Env Conserv. 2016. doi:10.1017/S0376892916000217.

52. Burdett CL, Crooks KR, Theobald DM, Wilson KR, Boydston EE, Lyren LM, Fisher RN, Winston Vickers T, Morrison SA, Boyce WM. Interfacing models of wildlife habitat and human development to predict the future distribution of puma habitat. Ecosphere. 2010;1:4

53. Linnell JDC, Swenson JE, Anderson R. Predators and people: conservation of large carnivores is possible at high human densities if management policy is favorable. Anim Conserv. 2001;4:345-9.

54. Balme GA, Batchelor A, De Woronin Britz N, Seymour G, Grover M, Hes L, MacDonald DW, Hunter LTB. Reproductive success of female leopards Panthera pardus: the importance of top-down processes. Mamm Rev. 2012;43:221-37.

55. White KR, Koehler GM, Maletzke BT, Wielgus RB. Differential prey use by male and female cougars in Washington. J Wildl Manage. 2011;75:1115-20.

56. Thompson DJ, Jenks JA. Dispersal movements of subadult cougars from the black hills: the notions of range expansion and recolonization. Ecosphere. 2010;1:1-10.

57. Lambert CM, Wielgus RB, Robinson HR, Cruickshank HS, Clarke R, Almack J. Cougar population dynamics and viability in the Pacific Northwest. J Wildl Manage. 2006;70:246-54.

58. Cooley HS, Wielgus RB, Koehler GM, Robinson HS, Maletzke BT. Does hunting regulate cougar populations? A test of the compensatory mortality hypothesis. Ecology. 2009;90:2913-21. 